\title{
A Brief Study of Conditionals in SLA
}

\author{
Hui Yan \\ School of Foreign Languages, Qingdao University of Science and Technology, Qingdao, China \\ Email:magyan@sohu.com
}

\begin{abstract}
Heated discussions of conditionals have been carried out from various theoretical aspects. In this article the author is trying to examine conditionals from truth-functionality, non-truth functionality, and suppositional theories and semantically from these three domains, thus offering a comprehensive understanding of conditionals.
\end{abstract}

Index Terms - conditionals, truth-functionality, non-truth functionality, suppositional theory, semantics

\section{INTRODUCTION}

Conditionality is a highly controversial subject in current linguistic analyses. Scholars have been studying conditionals with regard to four main theories: truth-functionality, non-truth functionality, suppositional theory and semantics. In the following article, the author intends to examine conditionals from such aspects so as to shed some light into a better understanding of them

\section{CONDITIONALS}

The analyses of conditionals from the definitions, classifications and four different theories are briefly presented respectively in the following.

\section{A. Definitions and Classifications}

Sweester (1990) holds that conditionals mean that the consequent is true in every case where the antecedent is true but not assuming that there is definitely a connection between the truth of the antecedent and the truth of the consequent. It is controversial how best to classify conditionals. Jackson (1991) insists that conditionals consist of two kinds, "indicative" and "subjunctive" or "counterfactual" conditionals. Indicative conditionals can be exemplified by sentences such as "We'll be home by ten if the train is on time", and "If Mary didn't cook the dinner, Tom cooked it". A conditional sentence "If A, C" or "C if A" thus has two contained sentences or sentence-like clauses. A is called the antecedent, C the consequent. If you understand $\mathrm{A}$ and $\mathrm{C}$, and you have mastered the conditional construction (as we all do at an early age), you understand "If A, C". If literally means "on condition that; provided that; supposing that". These are adequate synonyms. But we want more than synonyms. These examples are traditionally called "indicative conditionals", aiming to give an account of the conditional construction which explains when conditional judgments are acceptable, which inferences involving conditionals are good inferences, and why this linguistic construction is so important. There are also "subjunctive" or "counterfactual" conditionals like "Tom would have cooked the dinner if Mary had not done so", "We would have been home by ten if the train had been on time". That there is some difference between indicatives and counterfactuals is shown by pairs of examples like "If Oswald didn't kill Kennedy, someone else did" and "If Oswald hadn't killed Kennedy, someone else would have". Adams (1970) thinks that both two types are justified. That there is not a huge difference between them is shown by examples like the following: "Don't go in there", I say, "If you go in you will get hurt". You look skeptical but stay outside, when there is large crash as the roof collapses. "You see", I say, "if you had gone in you would have got hurt. I told you so."

Haiman (1986) declares that conditionality has a multi-faceted existence in the three basic domains of semantic interpretation. Conditionals thus exist in the content, epistemic and speech-act domains. In the content domain, conditional if-then conjunction indicates that the realization of the event or state of affairs described in the protasis is a sufficient condition for the realization of the event or state of affairs described in the apodosis. In the epistemic domain, if-then conjunction expresses the idea that knowledge of the truth of hypothetical premises expressed in the protasis would be a sufficient condition for concluding the truth of the proposition expressed in the apodosis. "If she's obtained a Bachelor's degree, (then) she has been studying in college" is such an example. In the usage of the formal-logical if-then structure, epistemic conditionals are the closest. There are a great range of conditional speech acts. Some explicitly refer to the general felicity conditions on the relevant class of speech acts whereas others refer implicitly to these general conditions with reference to some more specific felicity condition on the particular utterance such as a sub-case of the general condition. Van der Auwera(1986)illustrates the overt speech-act conditionals by pointing out that the performance of the speech act represented in the apodosis is conditional on the fulfillment of the state described in the protasis which enables or causes the following speech act. No matter what types of classifications are adopted, the essential characteristics are comprehensively viewed from four major theories. The theories to be discussed do not explain better or worse when restricted to a conditional, but they contribute from different aspects to the full 
understanding of conditionals.

\section{B. Truth-functionality}

Truth-functionality means that the truth value of the conditional is determined by the truth values of its parts and it follows that a conditional is always true when its components have these combinations of truth values. It is a strikingly simple theory: "If A, B" is false when A is true and B is false. In all other cases, "If A, B" is true. Viewed from the truth-functional theory, if "if" is truth-functional, this is the right truth function to attribute to it. First, it is uncontroversial that when $\mathrm{A}$ is true and $\mathrm{B}$ is false, "If $\mathrm{A}, \mathrm{B}$ " is false. A basic rule of inference is modus ponens: from "If $\mathrm{A}, \mathrm{B}$ " and $\mathrm{A}$, we can infer $\mathrm{B}$. If it were possible to have $\mathrm{A}$ true, $\mathrm{B}$ false and "If $\mathrm{A}, \mathrm{B}$ " true, this inference would be invalid. Second, it is uncontroversial that "If A, B" is sometimes true when A and B are respectively (true, true), or (false, true), or (false, false). "If it's a triangle, it has three sides", said of an unseen geometric figure, is true, whether the figure is a square, a rectangle or a triangle. Grice (1989) studies truth-functionality from the pragmatic point of view. Look at "If he's not in the pub he's in the library". The conditional, like the disjunction, according to Grice, is true if he's in the pub, but misleadingly asserted on that ground. There are many ways of speaking the truth yet misleading your audience, on the condition that you should follow some rituals in conversational exchanges. One way is to say something weaker than some other relevant thing you are in a position to say. Consider disjunctions. I am asked where John is. I am sure that he is in the pub, and know that he never goes near libraries. Inclined to be unhelpful but not wishing to lie, I say "He is either in the pub or in the library". My hearer naturally assumes that this is the most precise information I am in a position to give, and also concludes from the truth (let us assume) that I told him "If he's not in the pub he's in the library". The conditional, like the disjunction, according to Grice, is true if he's in the pub, but will be misleadingly asserted on that ground.

Lewis (1976) also offers a typical example: "You won't eat those and live". As an expert in mushrooms, the speaker's advice is definitely to be obeyed by the listener. The speaker told no lie — for indeed you don't eat them — but of course he misled you. Truth-functionality is equally right about disjunctions and negated conjunctions. Grice drew attention, then, to situations in which a person is justified in believing a proposition, which would nevertheless be an unreasonable thing for the person to say in normal circumstances. Believing that mushrooms are poisonous, I can't consistently disbelieve "You won't eat those and live". It is hard to believe that the difficulties with the truth-functional conditional can be explained away in terms of what is an improper conversational remark. They arise at the level of belief and the norms. On anyone's account of conditionals, there will be circumstances when a conditional is justifiably believed, but is liable to mislead if stated.

\section{Non-truth Functionality}

Non-truth-functionality insists that "If A, B" is false when A is true and B is false; and they agree that the conditional is sometimes true for the other three combinations of truth-values for the components; but they deny that the conditional is always true in each of these three cases. Read (1995) thinks that when A is false, "If A, B" may be either true or false. For instance, Jack says, "If you drink this bottle of water, you will suffer from the diarrhea ". You don't drink it. Was his remark true or false? According to the non-truth-functionalist, it depends on whether the bottle of water is clean and so forth. Stalnaker (1968) points out that a possible situation in which you drink this bottle of water, and which otherwise differs minimally from the actual situation. The conditional is true or false according to whether or not you have a diarrhea in that possible situation. Edgington (1995) puts forward two formulae of truth-functionality and non-functionality interpretations which explicitly demonstrate the differences between the two. Suppose A and B are two logically independent propositions. The four lines below represent the four incompatible logical possibilities for the truth values of A and B. "If A, B", "If $\sim \mathrm{A}, \mathrm{B}$ " and "If A, $\sim \mathrm{B}$ " are interpreted truth-functionally in columns (i)-(iii), and non-truth-functionally (when their antecedents are false) in columns (iv)-(vi). The non-truth-functional interpretation we write "A $\rightarrow \mathrm{B}$ ". "T/F" means both truth values are possible for the corresponding assignment of truth values to $\mathrm{A}$ and $\mathrm{B}$. For instance, line 4, column (iv), represents two possibilities for A, B, If A, B, (F, F, T) and (F, F, F).

The interpretations by Edgington (1995) are based on the natural deduction. Suppose you start off with no information about which of the four possible combinations of truth values for A and B obtains. You then acquire convincing reason to think that either A or B is true. You don't have any stronger belief about the matter. In particular, you have no firm belief as to whether A is true or not. You have ruled out line 4. The other possibilities remain open. Then, intuitively, you are justified in inferring that if $\sim$ A, B. Look at the possibilities for A and B on the left. You have eliminated the possibility that both A and B are false. So if A is false, only one possibility remains: B is true. The truth-functionalist (call him Hook) gets this right. Look at column (ii). Eliminate line 4 and line 4 only, and you have eliminated the only possibility in which " A $\supset$ B" is false. You know enough to conclude that " A $\supset$ B" is true. The non-truth-functionalist (call her Arrow) gets this wrong. Look at column (v). Eliminate line 4 and line 4 only, and some possibility of falsity remains in other cases which have not been ruled out. By eliminating just line 4 , you do not thereby eliminate these further possibilities, incompatible with line 4 , in which " $\sim \mathrm{A} \rightarrow \mathrm{B}$ " is false. The same point can be made with negated conjunctions. You discover for sure that $\sim(A \& B)$, but nothing stronger than that. In particular, you don't know whether A. You rule out line 1, nothing more. You may justifiably infer that if A, B. Hook gets this right. In column (iii), if we eliminate line 1, we are left only with cases in which "A $\supset \sim \mathrm{B}$ " is true. Arrow gets this wrong. In column (vi), eliminating line 1 leaves open the possibility that "A $\rightarrow \sim \mathrm{B}$ " is false. The same argument renders 
convincing the thought that if we eliminate just $A \& \sim B$, nothing stronger, i.e., we don't eliminate $A$, then we have sufficient reason to conclude that if $\mathrm{A}, \mathrm{B}$.

\section{Suppositional Theory}

A suppositional theory was first advanced by Mackie (1973) and further developed by Adams (1970). It emphasizes the fact that conditionals can be accepted with different degrees of closeness to certainty. Make the idealizing assumption that degrees of closeness to certainty can be quantified: $100 \%$ certain, $90 \%$ certain, etc.; and we can turn to probability theory for what Ramsey called the "logic of partial belief". There we find a well-established, indispensable concept, "the conditional probability of B given A". It is to this notion that Ramsey refers by the phrase "degrees of belief in q given $\mathrm{p}$ ". It is, at first sight, rather curious that the best-developed and most illuminating suppositional theory should place emphasis on uncertain conditional judgments. If we knew the truth conditions of conditionals, we would handle uncertainty about conditionals in terms of a general theory of what it is to be uncertain of the truth of a proposition. But there is no consensus about the truth conditions of conditionals. It happens that when we turn to the theory of uncertain judgments, we find a concept of conditionality in use. It is worth seeing what we can learn from it.

The notion of conditional probability entered probability theory at an early stage because it was needed to compute the probability of a conjunction. Bayes (1763) points out that "The probability that two ... events will both happen is ... the probability of the first [multiplied by] the probability of the second on the supposition that the first happens [my emphasis]."Such example are numerous. You are about 50\% certain that the test will be on conditionals and about $80 \%$ certain that you will pass, on the supposition that it is on conditionals. So you are about $40 \%$ certain that the test will be on conditionals and you will pass. Let's look at the truth table again. You are wondering whether if A, B. Assume A. That is, ignore lines 3 and 4 in which $\mathrm{A}$ is false. Ask yourself about the relative probabilities of lines 1 and 2 . Suppose you think line 1 is about 100 times more likely than line Then you think it is about 100 to 1 that B if A. To make the point in a slightly different way, let me adopt the following as an expository, heuristic device, a harmless fiction. Imagine a partition as carved into a large finite number of equally-probable chunks, such that the propositions with which we are concerned are true in an exact number of them. The probability of any proposition is the proportion of chunks in which it is true. The probability of B on the supposition that $\mathrm{A}$ is the proportion of the A-chunks (the chunks in which $\mathrm{A}$ is true) which are B-chunks. With some misgivings, I succumb to the temptation to call these chunks "worlds": they are equally probable, mutually incompatible and jointly exhaustive epistemic possibilities, enough of them for the propositions with which we are concerned to be true, or false, at each world. The heuristic value is that judgments of probability and conditional probability then translate into statements about proportions.

By a different argument, Lewis (1976) was the first to prove this remarkable result: there is no proposition $A * B$ such that, in all probability distributions, $\mathrm{p}(\mathrm{A} * \mathrm{~B})=\mathrm{pA}(\mathrm{B})$. A conditional probability does not measure the probability of the truth of any proposition. If a conditional has truth conditions, one should believe it to the extent that one thinks it is probably true. If Supp is correct, that one believes "If A, B" to the extent that one thinks it probable that B on the supposition that $\mathrm{A}$, then this is not equivalent to believing some proposition to be probably true. Hence, if Supp is right, conditionals shouldn't be construed as having truth conditions at all. A conditional judgment involves two propositions, which play different roles. One is the content of a supposition. The other is the content of a judgment made under that supposition. They do not combine to yield a single proposition which is judged to be likely to be true just when the second is judged likely to be true on the supposition of the first.

\section{E. Semantic Theory}

The studies of conditionality in the three semantic domains are conducted systematically. Conditionality is widely discussed within the range of content conditionals, epistemic conditionals and speech-act conditionals. Conditionals in the content domain with conditional if-then conjunction indicate that the connection between antecedent and consequent may be a casual one. "If Alice goes, Tom will go". Alice's going might lead to Tom's going, or Alice's not going could in some way result in Tom's not going. Thus this sentence means that if the real-world state of affairs includes Mary's going, then it will also include John's going. Depending on the pragmatic context and the linguistic form, the fulfillment of the sufficient condition presented in the protasis may appear more or less likely. Epistemic conditionals demonstrate our understanding of our logical reasoning processes, and hence reflect to some extent the same structures inherent in a more formal-mathematical understanding of logic. But they are not enough to ensure the felicitousness of an epistemic conditional any more than that of a content conditional. Epistemic conditionals have some presumed relationship between the clauses. The connection between the contents of the two clauses is so complex that sometimes the relationship is assumed to be related. The understanding of it may require a considerable number of context relating protasis and apodosis, completely unlike the simple truth-value requirements imposed by a logical if-then.

There exist a wide range of conditional speech acts. On the one hand, Van der Auwera(1986)illustrates the overt speech-act conditionals by pointing out that the performance of the speech act represented in the apodosis is conditional on the fulfillment of the state described in the protasis which enables or causes the following speech act. The conditions on conditional speech acts are obvious statements in the sort of the general appropriateness-conditionals discussed. This way is parallel to the way in which speech-act uses of or present two alternative speech acts. Counting on the interlocutor's cooperation in helping keep some jointly agreed-on mental record of what counts as "really" having been said, and on a commonly-accepted knowledge that conditionally records a conditional speech act, these conditional 
speech acts are actually performed but present themselves as only conditionally performed. On the other hand, Searle(1969)also states that there exist implicit functioning of speech-act conditionals. Those statements are likely to induce ambiguity. First, it could be asserted that the previous "goings to the movies" correspond to Mary's presence. Then, it could be understood that if John went to the cinema, I ask him whether Mary was there. Therefore, the understanding of this speech-act conditional relies on the condition that the hearer has the relevant knowledge. The difference between the felicitous and implicit conditionals is whether the speaker already knows the answer or not. If the speaker knows the answer, then the question is unnecessary. As the speaker doesn't know, the question is asked not on the explicit condition that the previous going to the movies would enable the hearer to answer the question but on the implicit condition that the past going to the movies would make the question relevant.

Dancygier (1987) claims that conditionals have a separate metalinguistic use. He suggests that these metalinguistic uses of conditionals should be carefully distinguished from the standard conditional speech acts. The conditionals are understood linguistically rather than lexically. Von Wright (1975) points out that the three different types of conditionals vary regarding protasis and apodosis. Content conditionals do not need paraphrases involving speech acts or logical processes. Epistemic conditionals are paraphrased as the protasis "If I know" and the apodosis "then I conclude". The speech-act conditionals are properly paraphrased by the protasis "if" and the apodosis "then let us consider that I perform this speech act." Sometimes the distinction of conditionals in the three domains is quite difficult due to the difficult process of reasoning from apodosis to protasis as well as from protasis to apodosis. As a result, content conditionals specify the relationship and dependency not only between the truth values of the two clauses but also between their contents. With the epistemic conditionals, the protasis' truth makes up a sufficient condition for concluding the truth of the apodosis, because the knowledge of the protasis is taken as causing or enabling the conclusion embodied in the apodosis. The apodoses of the conditional speech-acts often have no truth values, because they can be questions, commands, or requests as easily as assertions. Conditional speech-acts invariably require an interpretation wherein the protasis expresses a factor which actively influences the performance of the following speech act.

\section{CONCLUSION}

In sum, the above range of discussions of conditionals from four types of theories offers a holistic base for the holistic and objective understanding of conditionality, thus paving the way for further related studies.

\section{REFERENCES}

[1] Adams, E. W. (1970). Subjunctive and Indicative Conditionals. Foundations of Language, 6, pp.89-94.

[2] Bayes, T. (1763). An Essay Towards Solving a Problem in the Doctrine of Chances. Transactions of the Royal Society of London, 53, pp. 370-418.

[3] Dancygier, B. (1987). Conditionals and relevance. Paper presented at the 1987 International Pragmatics Conference in Antwerp.

[4] Edgington, D. (1995). On Conditionals. Mind 104, pp. 235-329.

[5] Grice, H. P. (1989). Studies in the Way of Words. Cambridge MA: Harvard University Press.

[6] Haiman, J. (1986). Constraints on the form and the meaning of the protasis. In E.C. Traugott, A. Jackson, F. (ed.). (1991). Conditionals. Oxford: Clarendon Press.

[7] Lewis, D. (1976). Probabilities of Conditionals and Conditional Probabilities. Philosophical Review, 85, pp. 297-315.

[8] Mackie, J. L. (1973). Truth, Probability and Paradox. Oxford: Clarendon Press.

[9] Read, S. (1995). Conditionals and the Ramsey Test. Proceedings of the Aristotelian Society Supplementary. 69, pp. 47-65.

[10] Searle, J. R. (1969). Speech acts: an essay in the philosophy of language. Cambridge: Cambridge University Press.

[11] Stalnaker, R. (1968). A theory of conditionals. In Rescher, N., (ed). Studies in logical theory, number 2 in American philosophical quarterly monograph series. Blackwell, Oxford.

[12] Sweester, E. (1990). From etymology to Pragmatics: Metaphorical and Cultural Aspects of Semantic Structure. Cambridge: Cambridge University Press.

[13] Van der Auwera, J. (1986). Conditionals and speech acts. In E. C. Traugott, A. ter Meulen, J. S. Reilly \& C. A. Ferguson. (eds.). On Conditionals. pp.197-214. Cambridge: Cambridge University Press.

[14] Von Wright, G. H. (1975). On the logic and epistemology of the casual relation. In Sosa and Tooley Good (eds.), Causation, 105-124.

Hui Yan was born in Shaanxi Province, China in 1971. She received her M.A. in English from Peking University, China in 2000.

She's currently a lecturer in the school of foreign languages, Qingdao University of Science and Technology, Qingdao, China. Her research interests include SLA and cross-cultural communication. Miss Yan is a member of the Chinese Association of Foreign Language Teachers. 